\title{
Preparation of Electromagnetic Shielding Coating Based on Natural Rubber
}

\author{
Nguyen Thu $\mathrm{Ha}^{1}{ }^{1, *}$, Cao Hong $\mathrm{Ha}^{1}$, Do Le Viet Hung ${ }^{1}$, Nguyen Pham Duy Linh ${ }^{1}$, Tran Thi Thuy ${ }^{1}$, \\ Phan Trung Nghia ${ }^{1}$, Seiichi Kawahara ${ }^{2}$ and Toshiaki Ougizawa ${ }^{3}$ \\ ${ }^{1}$ School of Chemical Engineering, Hanoi University of Science and Technology, No. 1 Dai Co Viet street, Hai Ba Trung district, \\ Hanoi, Vietnam \\ ${ }^{2}$ Department of Materials Science and Technology, Nagaoka University of Technology, Nagaoka 940-2188, Japan \\ ${ }^{3}$ Tokyo Institute of Technology, Tokyo 152-8550, Japan
}

\begin{abstract}
In this study, natural rubber-based electromagnetic shielding materials for coating application were made. Expanded graphite was prepared using our method and dispersed in the polyaniline/natural rubber matrix. The effect of PAni and expanded graphite on the properties of resulting materials was evaluated. The characterization of properties that are important for an electromagnetic shielding coating (i.e., mechanical properties, electromagnetic shielding, wettability resistance, thermal properties, and the morphology of the material) was investigated. The result shows that the properties of natural rubber/polyaniline blends are enhanced owing to the presence of expanded graphite. The superior properties are achieved when the amount of added expanded graphite in natural rubber/polyaniline is 5 parts per $100 \mathrm{~g}$ of natural rubber. The enhancement of properties is attributed to the good dispersion of expanded graphite in the natural rubber/polyaniline matrix, which improves the compatibility of the natural rubber and polyaniline phase. [doi:10.2320/matertrans.MT-MN2019010]
\end{abstract}

(Received December 20, 2019; Accepted February 25, 2020; Published July 25, 2020)

Keywords: natural rubber, polyaniline, expanded graphite, compatibility, electromagnetic shielding, coating material

\section{Introduction}

Electromagnetic shielding coatings have attracted considerable interest because they are essential to the military and also in daily life. The coatings may be magnetic loss absorbents, electric loss absorbents, or dielectric loss absorbents. ${ }^{1-3)}$ To be suitable for practical application, the electromagnetic absorbing coatings have to possess specific properties such as light specific gravity, high wettability resistance, good plasticity, and high ability to cover a protected surface. Thus, conductive polymer-based coatings are expected to meet the abovementioned requirement. ${ }^{4,5)}$

Polyaniline (PAni) is a polymer of choice. PAni is one of the most commonly studied conductive polymers owing to its simple preparation procedure, thermal resistibility, and oxidation resistibility. ${ }^{6-8)}$ The superior physical and chemical properties of PAni originate from its unique $\pi$ electron conjugated system. However, owing to the $\pi$ electron conjugated system, PAni is very rigid, and infusible. Whereas, natural rubber (NR), which is an elastomer obtained by tapping rubber tree Hevea Brasiliensis, is known for its outstanding mechanical properties such as tensile strength, tear strength, and green strength. ${ }^{9,10)}$ Moreover, NR has already become more attractive compared to synthetic rubber as a renewable resource. The blend of PAni and NR is expected to result in a material which is an ideal electromagnetic shielding coating. However, the compatibility of PAni and NR may be poor owing to the different polarity of these polymers. Thus, it is difficult to blend PAni and NR. ${ }^{11)}$

The compatibility of two-component system of NR and PAni may be improved if the third component, which is miscible in both NR and PAni, is added. ${ }^{12)}$ Graphite may be used to improve the compatibility between PAni and NR because it can disperse well in both. In addition, graphite

*Corresponding author, E-mail: ha.nguyenthu5@hust.edu.vn is anticipated to enhance the electromagnetic shielding of the materials. ${ }^{13)}$ It is necessary to increase the dispersity of graphite. Therefore, the modification to expand graphite sheets may be used to prepare graphite with better dispersity.

In this study, the preparation of expanded graphite (EG) from commercial graphite was performed, followed by an attempt to disperse EG in the PAni/NR matrix. NR/PAni blends and NR/PAni/EG with various PAni contents were subjected to efficient vulcanization with N-cyclohexylbenzothiazole-2-sulphenamide as an accelerator. We investigated the effect of PAni and EG on the crosslink density, mechanical properties, electromagnetic shielding efficiency, contact angle of liquids on the surface, and thermal properties to identify suitable materials that are based on NR for electromagnetic shielding coating.

\section{Experimental}

\subsection{Materials}

Ribbed smoked sheet NR (RSS3) was the commercial product of Phu Rieng Co., Ltd., Vietnam. Polyaniline (99.9 mass\% purity) with the conductivity of $7.5 \mathrm{~S} / \mathrm{cm}$ was purchased from Beijing Mayor Chemical Technology Co., Ltd. Zinc oxide (99.9 mass\% purity), stearic acid (99.5 mass $\%$ purity), sulfur (99.9 mass $\%$ purity), and N-cyclohexylbenzothiazole-2-sulphenamide (CZ, 99.8 mass\% purity) were the products of Nacalai Tesque Inc. Sulfuric acid (98 mass\% purity), potassium dichromate (99 mass\% purity), acetic anhydride ( 99.5 mass \% purity), and toluene (99.9 mass $\%$ purity) were purchased from Sae Kwang Chemical Inc. Co. Ltd. The chemicals were used without further treatment.

\subsection{Preparation of samples}

\subsubsection{Preparation of expanded graphite}

Fine EG was prepared from fine natural flake graphite (99\% C, 250 mesh) from Yen Bai province, Vietnam. The 
Table 1 Composition of compounds (phr).

\begin{tabular}{ccccccccc}
\hline No. & Sample & NR & PAni & ZnO & $\begin{array}{c}\text { Stearic } \\
\text { acid }\end{array}$ & Sulfur & CZ & $\begin{array}{c}\text { Expanded } \\
\text { graphite }\end{array}$ \\
\hline 1 & & & & & & & & \\
2 & NR & 100 & - & 5.0 & 2.0 & 0.6 & 7.2 & - \\
3 & NR/PAni10 & 100 & 5.0 & 5.0 & 2.0 & 0.6 & 7.2 & - \\
4 & 100 & 10.0 & 5.0 & 2.0 & 0.6 & 7.2 & - \\
5 & NR/PAni12 & 100 & 12.0 & 5.0 & 2.0 & 0.6 & 7.2 & - \\
6 & NR/PAni10/EG1 & 100 & 10.0 & 5.0 & 2.0 & 0.6 & 7.2 & 1.0 \\
7 & NR/PAni10/EG3 & 100 & 10.0 & 5.0 & 2.0 & 0.6 & 7.2 & 3.0 \\
8 & NR/PAni10/EG5 & 100 & 10.0 & 5.0 & 2.0 & 0.6 & 7.2 & 5.0 \\
& & 100 & 10.0 & 5.0 & 2.0 & 0.6 & 7.2 & 7.0
\end{tabular}

preparation process was carried out in four steps: (1) natural flake graphite was mixed with sulfuric acid and potassium dichromate in a flask; then, this mixture was stirred at $150 \mathrm{rpm}$ for $20 \mathrm{~min}$; (2) acetic anhydride was slowly dripped into the flask with continuous stirring at $200 \mathrm{rpm}$ for $30 \mathrm{~min}$ and graphite intercalation compounds (GICs) were generated; (3) the mixture was filtered and washed with deionized water to reach $\mathrm{pH}$ neutrality, followed by drying at $353 \mathrm{~K}$ for $2 \mathrm{~h}$; (4) dried GICs underwent the "heat shock" step in a microwave at the power of $1000 \mathrm{~W}$ for $20 \mathrm{~s}$ to obtain EG.

\subsubsection{Vulcanization process}

The formulation to compound the blends of NR/Pani and NR/PAni/EG is presented in Table 1. The amounts of PAni, EG, and other components for vulcanization were calculated in parts per $100 \mathrm{~g}$ of NR (phr). Mixing of the compounds was performed at $373 \mathrm{~K}$ using an internal mixer. The optimal time for vulcanizing each compound was determined using a rotorless rheometer RLR-4 at $423 \mathrm{~K}$. The vulcanization of each compound was performed in a compression mold at $423 \mathrm{~K}$ with an optimal time.

\subsection{Characterization}

The crosslink density of the vulcanized rubber was determined by the swelling method. The rubber was immersed in $100 \mathrm{ml}$ of toluene that was kept in activated Molecular Sieves 4A in the dark for a week at room temperature. The crosslink density of the sample was determined through the Flory-Rehner equation:

$$
v=-\frac{1}{2 V_{s}} \frac{\ln \left(1-V_{r}\right)+V_{r}+X V_{r}^{2}}{\sqrt[3]{V_{r}}-\frac{1}{2} V_{r}}\left(\mathrm{~mol} / \mathrm{cm}^{3}\right)
$$

where $v$ is the crosslink density $\left(\mathrm{mol} / \mathrm{cm}^{3}\right), \mathrm{M}_{\mathrm{c}}$ is the molecular weight between crosslinks, $\mathrm{V}_{\mathrm{s}}$ is the molar volume of toluene $\left(106.52 \mathrm{~cm}^{3} / \mathrm{mol}\right), \mathrm{X}$ is the Flory-Huggins interaction parameter $(0.393) . \mathrm{V}_{\mathrm{r}}$ is the volume fraction of rubber, and was calculated using the equation:

$$
V_{r}=\frac{1}{\frac{\rho_{r}}{\rho_{s}}\left(\frac{W_{s}-W_{u}}{W_{u}}+1\right)}
$$

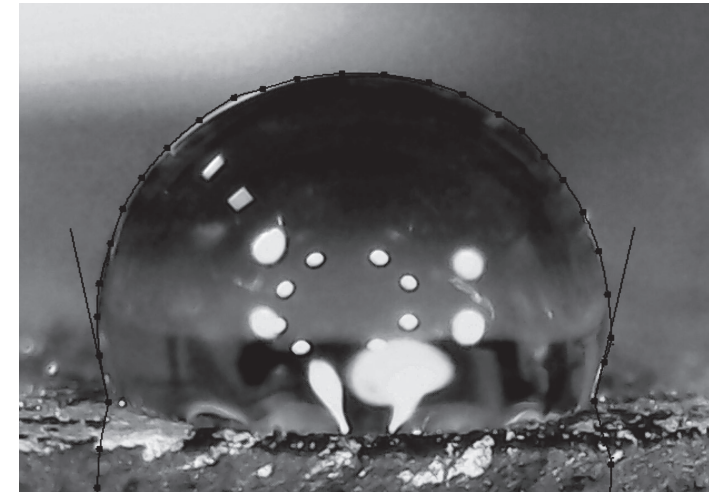

Fig. 1 Drop of liquid on the sample surface used for the contact angle measurement.

where $\rho_{\mathrm{r}}$ is the density of rubber $\left(0.913 \mathrm{~g} / \mathrm{cm}^{3}\right), \rho_{\mathrm{S}}$ is the density of toluene $\left(0.865 \mathrm{~g} / \mathrm{cm}^{3}\right), \mathrm{W}_{\mathrm{s}}$ is the mass of swollen rubber $(\mathrm{g})$, and $\mathrm{W}_{\mathrm{u}}$ is the mass of unswollen rubber $(\mathrm{g})$.

The tensile measurement of the samples was carried out using a Toyoseiki Strograph VG5E testing machine. The specimens were prepared by cutting 1.00 -mm-thick films into a dumbbell shape No. 7 with a dimension according to JIS K6251. The speed of crosshead was $200 \mathrm{~mm} / \mathrm{min}$. The measurement of tensile properties was repeated three times for each sample.

The contact angles of distilled water and IRM 901 oil on the surface of samples were measured. A drop of liquid (approximately $4 \mu \mathrm{L}$ ) was placed on the surface of the sample, as shown in Fig. 1. The contact angle was measured by the Dataphysics OCA20 system equipped with the SCA20 software. The measurement was carried out at $298 \mathrm{~K}$. The image of the drop was immediately taken by a CCD camera and sent to a computer for analysis.

The electromagnetic characterization of the sample was carried out using a N9918A Fieldfox vector network analyzer (Keysight Technologies). Samples with a thickness of $1 \mathrm{~mm}$ were prepared and subjected to the electromagnetic shielding measurement. Frequency was scanned in the range of 8 $12 \mathrm{GHz}$, and the reflection from the sample was measured. Shielding efficiency (SE) was calculated according to the following equation: 


$$
S E=10 \log \frac{P_{I}}{P_{T}}
$$

where $\mathrm{P}_{\mathrm{I}}$ and $\mathrm{P}_{\mathrm{T}}$ are the power of incident and transmitted $\mathrm{EM}$ waves, respectively.

Thermogravimetric analysis (TGA) for samples was carried out in a DTG-60H Shimadzu under argon atmosphere from room temperature to $973 \mathrm{~K}$. The heating rate was $10 \mathrm{~K} / \mathrm{min}$.

The sample packed into an aluminum pan was subjected to differential scanning calorimetry (DSC) measurements that were performed with DSC 7020 (SII NanoTechnology Inc.). The sample was heated from $183 \mathrm{~K}$ to $423 \mathrm{~K}$ at the heating rate of $10 \mathrm{~K} / \mathrm{min}$.

The surface morphology of samples was examined using a scanning electron microscopy (SEM) instrument Jeol SM200 operated at the accelerating voltage of $15 \mathrm{kV}$. The surface of the samples was sputter coated with a gold layer before analysis.

\section{Results and Discussion}

\subsection{Crosslink density}

The crosslink density of the samples is tabulated in Table 2. Table 2 shows that the crosslink density of NR and NR/PAni blends is not so different. This may imply that there was almost no linkage between NR phase and PAni phase formed during the vulcanization. ${ }^{14)}$ To investigate the effect of EG onto the crosslink density of NR/PAni, we prepared NR/PAni10/EG with various amounts of EG. The result shows that NR/PAni/EG blends contain higher crosslink densities than NR/PAni blends. Among the sample, NR/ PAni10/EG5 has the highest crosslink density. The high crosslink density of NR/PAni/EG means that EG enhances the interfacial interaction between NR and PAni. This may be the consequence of the good dispersion of EG in both NR phase and PAni phase, which decreased the interfacial tension between the two phases, which resulted in the compatibility. When the amount of EG was higher than $5 \mathrm{phr}$, EG agglomerates more easily, which reduced the effect of EG on the interface of NR and PAni phase.
Table 2 Crosslink density of the samples.

\begin{tabular}{ccc}
\hline No. & Sample & Crosslink density $\left(\times 10^{5}\right)$ \\
\hline 1 & NR & 6.25 \\
2 & NR/PAni5 & 6.47 \\
3 & NR/PAni10 & 6.59 \\
4 & NR/PAni12 & 6.41 \\
5 & NR/PAni10/EG1 & 6.88 \\
6 & NR/PAni10/EG3 & 8.94 \\
7 & NR/PAni10/EG5 & 12.77 \\
8 & NR/PAni10/EG7 & 10.52
\end{tabular}

\subsection{Mechanical properties}

Figure 2 illustrates the stress-strain curve of the samples. As can be observed in Fig. 2(a), the tensile strength of NR/ PAni blends is poor compared to that of NR. When the PAni content increased, the tensile strength of samples was considerably reduced. In fact, we realized that NR/PAni blends were much softer than NR. The phase separation in the NR/PAni blend may produce a negative effect on the mechanical properties. This observation is consistent with the result from the crosslink density measurement, which showed that NR and PAni were incompatible, and the linkages between NR phase and PAni phase was almost absent.

When EG was dispersed in the NR/PAni blend, it was found that EG significantly improved the tensile strength of the NR/PAni blend, as seen in Fig. 2(b). When the amount of EG increased, the tensile strength of the sample increased. NR/PAni/EG attained the highest tensile strength when the added EG was 5 phr. However, when the amount of EG was higher than $5 \mathrm{phr}$, the tensile strength of NR/PAni/EG slightly decreased. This was consistent with the result from the crosslink density of the samples. In this case, the 3Dnetwork formed in NR/PAni/EG limited the flow and mobility of polymer chains. ${ }^{15)}$ This mechanism distributed
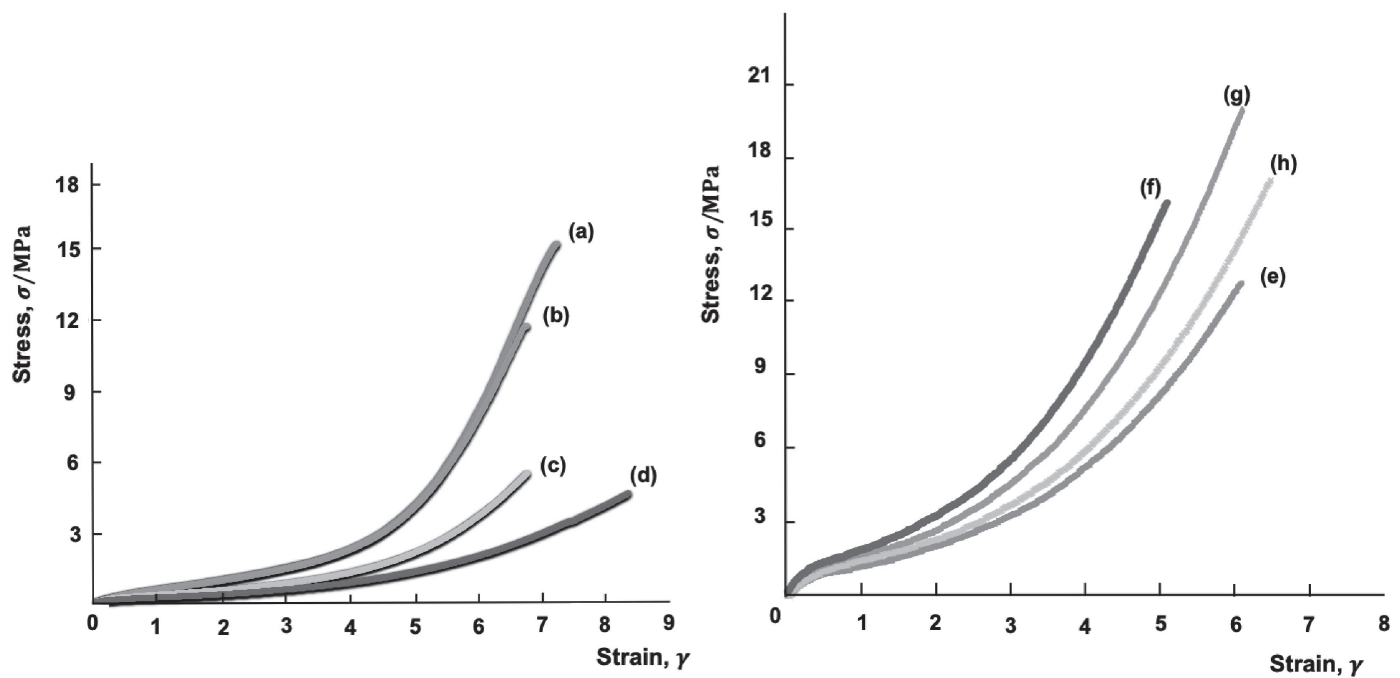

Fig. 2 Stress-strain curve of (a) NR, (b) NR/PAni5, (c) NR/PAni10, (d) NR/PAni12, (e) NR/PAni10/EG1, (f) NR/PAni10/EG3, (g) NR/PAni10/EG5, and (h) NR/PAni10/EG7. 
to the crystallization under stress, which resulted in high tensile strength. Furthermore, the stress-strain curves of NR/PAni and NR/PAni/EG were different in the stress at the strain value of 1 . The stress at strain value of 1 of NR/PAni/ EG is higher than that of NR/PAni. This may indicate that NR/PAni/EG blends are more resilient and more resistant to extrusion than NR/PAni blends.

\subsection{Wettability of surface}

Wettability of the sample surface was investigated in term of contact angle. Contact angle is defined as the angle formed by the intersection of the liquid-solid interface and the liquidvapor interface. The interface where solid, liquid, and vapor co-exist is referred to the "three-phase contact line." Small contact angles (less than $90^{\circ}$ ) correspond to high wettability, while large contact angles (greater than $90^{\circ}$ ) correspond to low wettability. The contact angle of water and oil on the surface of samples is tabulated in Table 3.

It can be seen that PAni lowers the waterproof of NR surface, as is evident in the smaller water contact angle on the NR/PAni surface compared to that on the NR surface. However, when EG was dispersed in the NR/PAni blend, the water contact angle increased. When the amount of added EG was $5 \mathrm{phr}$, the surface of the NR/PAni blend had the lowest water wettability. In the case of the oil contact angle, both PAni and EG supported the oil resistance of the sample. The higher were the amounts of PAni and EG, the greater was the contact angle. Briefly, EG increased both hydrophilicity and hydrophobicity of the NR/PAni/EG surface.

To clarify the effect of PAni and EG onto the surface characteristics of the samples, the sample surfaces was observed through SEM image as shown in Fig. 3. We

Table 3 Contact angle of the liquid on the surface of samples.

\begin{tabular}{ccc}
\hline Sample & Contact angle of water & Contact angle of oil \\
\hline NR & $113.3^{\circ}$ & $45.2^{\circ}$ \\
NR/PAni5 & $103.2^{\circ}$ & $47.7^{\circ}$ \\
NR/PAni10 & $105.0^{\circ}$ & $47.3^{\circ}$ \\
NR/PAni12 & $102.4^{\circ}$ & $53.0^{\circ}$ \\
NR/PAni10/EG1 & $105.5^{\circ}$ & $48.4^{\circ}$ \\
NR/PAni10/EG3 & $118.8^{\circ}$ & $49.5^{\circ}$ \\
NR/PAni10/EG5 & $128.1^{\circ}$ & $62.3^{\circ}$ \\
NR/PAni10/EG7 & $117.3^{\circ}$ & $63.7^{\circ}$
\end{tabular}

analyzed the surface of NR, NR/PAni10, and (3) NR/ Pani10/EG5. In the SEM image of NR, the surface is quite uniform, and the NR phase is observed. In the case of the $\mathrm{NR} /$ PAni blend, the protrusions which is the PAni phase on the surfaces were observed. The presence of the PAni phase on the surface may result in the small water contact angle and large oil contact angle of NR/PAni surface, because PAni is a polar polymer. In the surface of the NR/PAni/EG blend, the PAni- NR phase separation cannot be observed. This may be associated with the high crosslink density of NR/ PAni/EG. Therefore, the surface of the NR/PAni/EG blend became quite uniform, and the water resistance and oil resistance of NR/PAni/EG were improved.

\subsection{Electromagnetic shielding efficiency}

When the electromagnetic wave is incident on a shielding material, the reflection, transmission, absorption, and multiple reflections may occur. ${ }^{16)}$ Reflection loss is the result of interaction between conducting particles in the conducting material and electromagnetic field. ${ }^{17,18)}$ It is known that PAni and graphite are conducting materials in which vacancies and electrons are the conducting particles. Therefore, reflection dominates the shielding mechanism of NR/PAni and NR/ PAni/EG. When the conductivity of the materials is large, the magnetic permeability is small, and reflection loss is large.

Figure 4 shows the variation of shielding efficiency of the samples in the frequency range of $8-12 \mathrm{GHz}$. It is clear that with an increase in the amount of PAni in NR/PAni blends, the shielding efficiency increased. Furthermore, the shielding efficiency is enhanced in the presence of EG. In this case, EG improved not only the compatibility of the NR-PAni phase but also conductivity, which resulted in the reflection loss of NR/PAni/EG. Of note, the shielding efficiencies of NR/PAni10/EG1, NR/PAni10/EG3, NR/PAni10/EG5, and NR/PAni10/EG7 are similar. EG may be exfoliated in the $\mathrm{NR}$ and PAni phases to form the lamellae of graphite with a large specific surface area. Therefore, with the small amount of EG (e.g., 1 phr), the shielding efficiency of materials was considerably improved compared to that of NR/PAni.

\subsection{Thermal stability}

TGA is a useful method for the evaluation of the thermal stability of NR/PAni and NR/PAni/EG blends. The relative mass composition of these materials is easily determined by the mass loss owing to the volatilization and decomposition. Herein, we used NR, NR/PAni10 and NR/PAni10/EG5 for

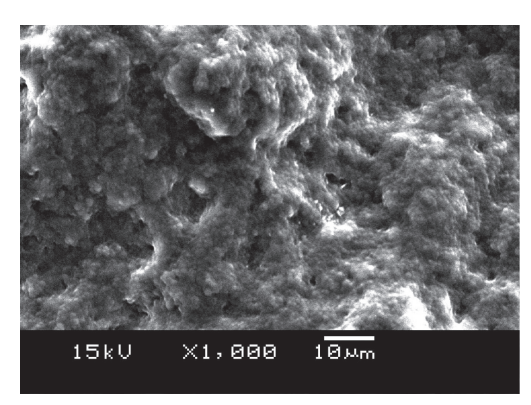

(a)

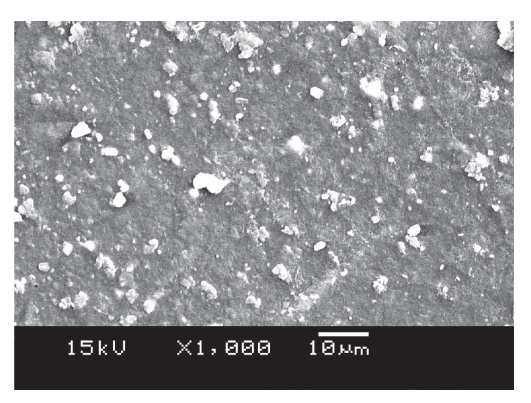

(b)

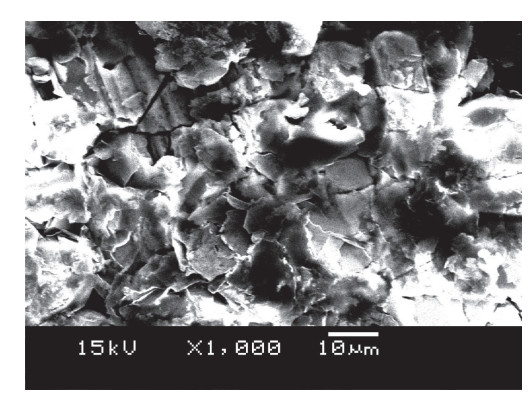

(c)

Fig. 3 SEM image of the sample surfaces (a) NR, (b) NR/PAni10, and (c) NR/Pani10/EG5. 


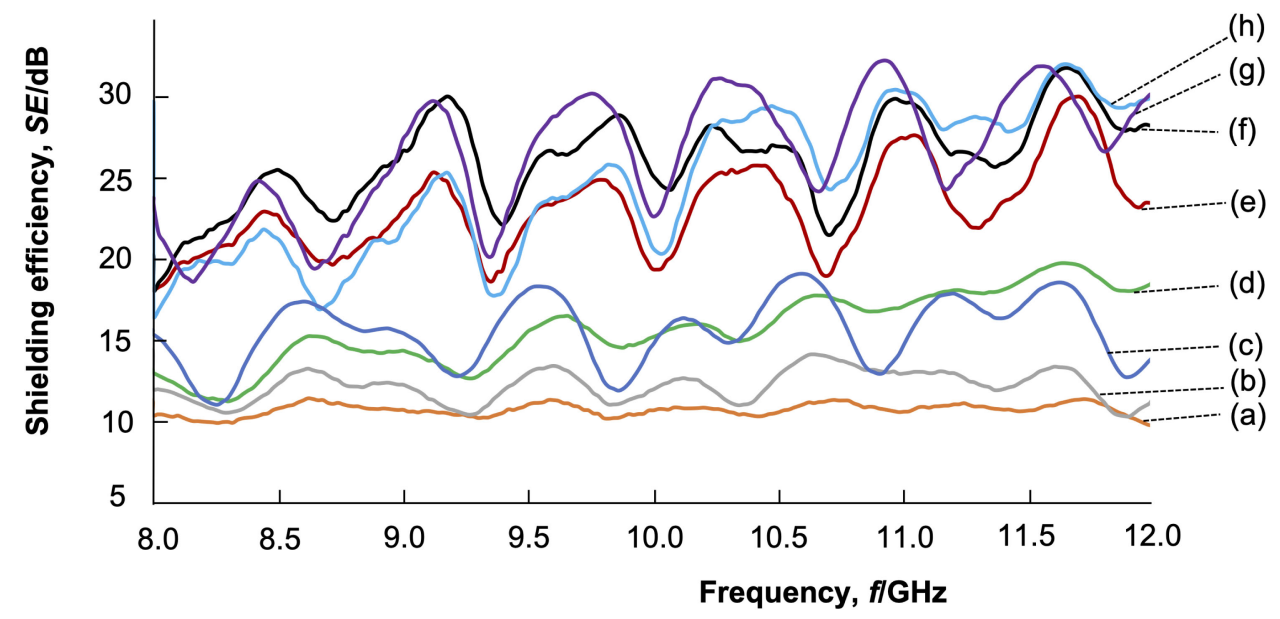

Fig. 4 Shielding efficiency of the samples (a) NR, (b) NR/PAni5, (c) NR/PAni10, (d) NR/PAni12, (e) NR/PAni10/EG1, (f) NR/ PAni10/EG3, (g) NR/PAni10/EG5, and (h) NR/PAni10/EG7.

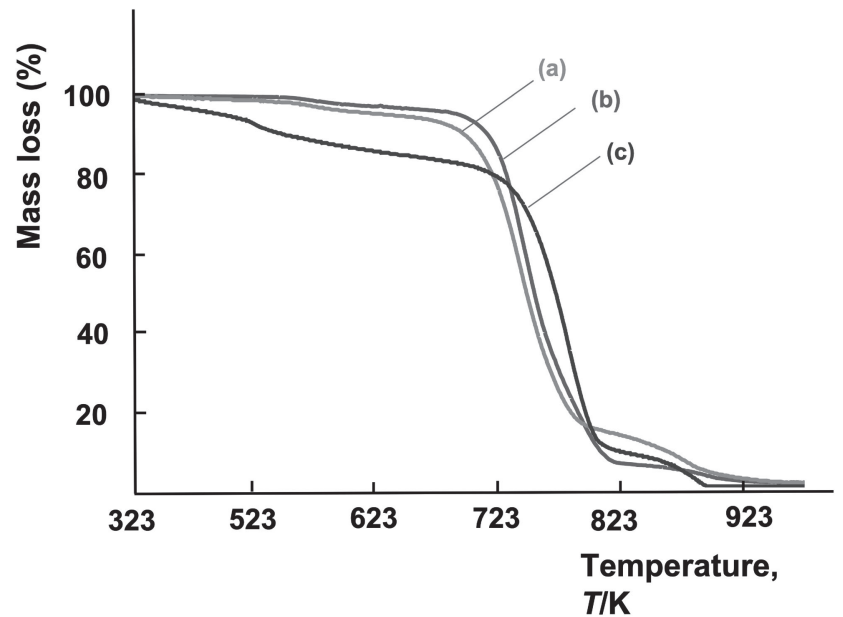

Fig. 5 TGA thermogram of the samples (a) NR, (b) NR/PAni10, and (c) NR/PAni10/EG5.

the TGA measurement. The TGA thermogram of the samples is shown in Fig. 5. The thermogram of NR and NR/PAni/ EG is similar, whereas that of NR/PAni is different. The thermogram of NR/PAni showed the gradual mass loss from $323 \mathrm{~K}$ to $743 \mathrm{~K}$. This may be associated with the elimination of dopant in PAni and with water being absorbed in NR/ PAni. ${ }^{19)}$ In the temperature range from $743 \mathrm{~K}$ to $883 \mathrm{~K}$, the mass loss may be attributed to the breakdown of the main chains in the polymer.

The TGA curves of NR and NR/PAni/EG have the same shape. However, NR/PAni/EG is more thermally stable than NR. Clearly, the initial decomposition temperature of NR/ PAni/EG is higher than that of NR. The loss of dopant and water absorbed in the sample cannot be observed in NR/ PAni/EG. The crosslink network formed by EG in NR/ PAni/EG may restrict the elimination of these components.

\subsection{Characterization of NR phase-PAni phase inter- action}

To evaluate the interaction between NR and PAni phases in the presence of EG, the glass transition temperature $\left(\mathrm{T}_{\mathrm{g}}\right)$ of the sample was determined via the DSC measurement. The DSC thermograms of NR, NR/PAnilo, and NR/PAni10/

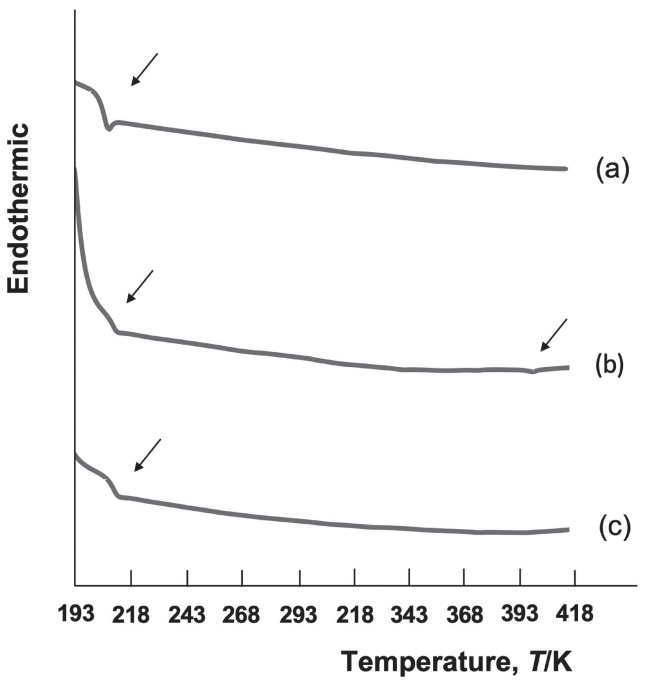

Fig. 6 DSC thermogram of the samples (a) NR, (b) NR/PAni10, and (c) NR/Pani10/EG5.

EG5 are illustrated in Fig. 6. In the thermogram of NR, the glass transition at $209.5 \mathrm{~K}$ can be observed. In the thermogram of the NR/PAni blend, there are two glass transitions present at $211 \mathrm{~K}$ and $398.8 \mathrm{~K}$, which correspond to $\mathrm{T}_{\mathrm{g}}$ of rubber and PAni phases, respectively. ${ }^{20,21)}$ It was clear that when NR was blended with PAni, $T_{g}$ of the NR phase slightly increased. The interaction between NR and PAni phases may hinder the motion of the rubber chain. ${ }^{22)}$ In the thermogram of NR/PAni10/EG5, $\mathrm{T}_{\mathrm{g}}$ of the NR phase is $212.5 \mathrm{~K}$, whereas $T_{g}$ of the PAni phase cannot be observed. This evidence may confirm that EG improved the compatibility of NR and PAni.

NR phase and PAni phase in sample may be observed via SEM image. Figure 7 shows the SEM images of EG and the fractured surface of NR/PAni10, and NR/PAni10/EG5. The expansion of graphite sheet was clearly observed from the morphology of EG, which is worm-like. It is observed through the fracture face of the NR/PAni blend that the zones of NR and PAni separated. The NR phase with the size of approximately $30-50 \mu \mathrm{m}$ was observed. The PAni phase was observed as the partiles aggregated in the sample. This 


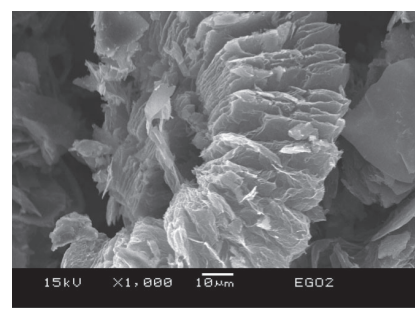

(a)

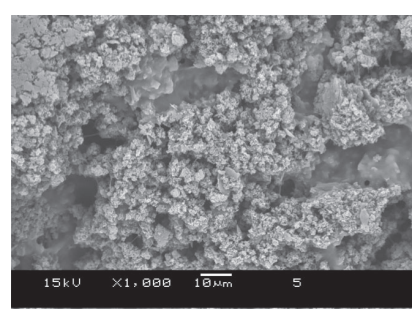

(b)

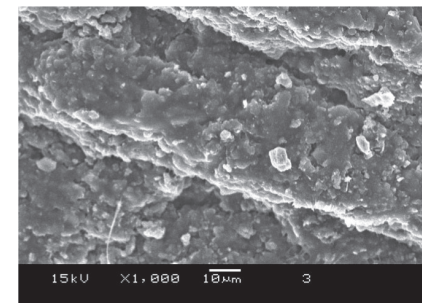

(c)

Fig. 7 SEM image of the samples (a) EG, (b) NR/PAni10, and (c) NR/ PAni10/EG5.

confirms the phase separation of PAni-NR in the blend. In NR/PAni/EG, PAni was determined to have good dispersibility in the NR phase, as seen in the fracture surface of NR/ PAni/EG, which is uniform. There were no PAni aggregate zone and NR zone observed. Moreover, graphite sheets with a primary shape cannot be seen in the SEM image of NR/ PAni/EG. It is assumed that graphite sheets were exfoliated and dispersed as small lamellae in the NR and PAni matrix. These lamellae may have strong interactions with both NR and PAni owing to their large specific surface area. This characteristic improved the properties of NR/PAni even though the amount of EG was small.

The observation in SEM image and $\mathrm{T}_{\mathrm{g}}$ of the samples was in good agreement with the results from other measurements reported in the previous sections. The uniformity in structure of NR/PAni/EG blend may result in its outstanding properties, e.g., mechanical properties, electromagnetic shielding, wettability resistance and thermal properties.

\section{Conclusion}

The mechanical properties, thermal properties, wettability resistance, and electromagnetic shielding efficiency of the NR/PAni blend were improved in the presence of EG. The optimal content of EG in NR/PAni is $5 \mathrm{phr}$. The characterization of glass transition and morphology of NR/PAni/EG confirmed that EG was well dispersed in NR and PAni phase and improved their compatibility. The NR/PAni/EG blend was determined to be suitable for electromagnetic shielding materials for coating application.

\section{Acknowledgments}

This work was supported by National Foundation for Science and Technology Development (grant code NAFOSTED 104.02-2017.20).

\section{REFERENCES}

1) L.C. Folgueras and M.C. Rezende: Mater. Res. 11 (2008) 245-249.

2) W. Schnabel: Polymers and Electromagnetic Radiation, (Wiley-VCH Verlag, Weinheim, 2014) pp. 7-46.

3) F. Parodi: Comprehensive Polymer Science, (Pergamon, Oxford, 1996) pp. 667-682.

4) A.K. Bakhshi and G. Bhalla: J. Sci. Ind. Res. 63 (2004) 715-728.

5) C.R. Martins, R. Faez, M.C. Rezende and M.-A. De Paoli': Polym. Bull. 51 (2004) 321-326.

6) G. Ćirić-Marjanović: Synth. Met. 177 (2013) 1-47.

7) E.W. Paul, A.J. Ricco and M.S. Wrighton: J. Phys. Chem. 89 (1985) 1441-1447.

8) H. Nakano, K. Hayashi, S. Oue and S. Kobayashi: Mater. Trans. 57 (2016) 1319-1326.

9) S. Amnuaypornsri, J. Sakdapipanich, S. Toki, B.S. Hsiao, N. Ichikawa and Y. Tanaka: Rubber Chem. Technol. 81 (2008) 753-766.

10) S. Kawahara, T. Kawazura, T. Sawada and Y. Isono: Polymer 44 (2003) 4527-4531.

11) K.F. Freed and J.D. James: Adv. Polym. Sci. 183 (2005) 63-126.

12) P. Atkins and J. de Paula: Physical Chemistry, (Oxford University Press, Oxford, 2006) pp. 174-192.

13) J. Huang, Y. Zhu, L. Xu, J. Chen, W. Jiang and X. Nie: Compos. Sci. Technol. 129 (2016) 160-165.

14) H.E. Adams and B.L. Johnson: Ind. Eng. Chem. 45 (1953) 1539-1546.

15) A.K. Mikitaev, M.K. Ligidov and G.E. Zaikov: Polymers, Polymer Blends, Polymer Composites and Filled Polymers: Synthesis, Properties, Application, (Nova Science Publishers, Inc., New York, 2006) pp. 25-31.

16) Y.K. Hong, C.Y. Lee, C.K. Jeong, D.E. Lee, K. Kim and J. Joo: Rev. Sci. Instrum. 74 (2003) 1098-1102.

17) D. Yuping, L. Shunhua and G. Hongtao: Sci. Technol. Adv. Mater. 6 (2005) 513-518.

18) Y. Dai, J. Wu, D. Wang, C. Lu and Z. Xu: Mater. Trans. 59 (2018) 876882 .

19) M. Thangarathinavelu, A.K. Tripathi, T.C. Goel and I.K. Varma: J. Appl. Polym. Sci. 51 (1994) 1347-1349.

20) N.T. Ha, K. Kaneda, Y. Naitoh, L. Fukuhara, K. Kosugi and S. Kawahara: J. Appl. Polym. Sci. 132 (2015) 42435.

21) M. Farbod and S.K. Tadavani: J. Non-Cryst. Solids 358 (2012) 13391344.

22) Y. Tanaka, Y. Nakahara and K. Takemoto: Angew. Makromol. Chem. 191 (1991) 71-80. 